Check for updates

Cite this: RSC Adv., 2018, 8, 36521

\title{
Stabilization of beryllium-containing planar pentacoordinate carbon species through attaching hydrogen atoms $\uparrow$
}

\author{
Xue-Feng Zhao, ${ }^{a}$ Jian-Hong Bian, ${ }^{a}$ Fang Huang, (D) Caixia Yuan, ${ }^{\text {c }}$ Qiang Wang, (DD *b \\ Ping Liu, ${ }^{\text {b }}$ Debao Li, ${ }^{\text {b }}$ Xiaotai Wang (D) ${ }^{d}$ and Yan-Bo Wu (D) *ab
}

\begin{abstract}
The diagonal relationship between beryllium and aluminum and the isoelectronic relationship between $\mathrm{BeH}$ unit and $\mathrm{Al}$ atom were utilized to design nine new planar and quasi-planar pentacoordinate carbon (ppC) species $\mathrm{CAl}_{n} \mathrm{Be}_{m} \mathrm{H}_{x}{ }^{q}(n+m=5, q=0, \pm 1, x=q+m-1)(1 \mathrm{a}-9 \mathrm{a})$ by attaching $\mathrm{H}$ atoms onto the $\mathrm{Be}$ atoms in $\mathrm{CAl}_{4} \mathrm{Be}, \mathrm{CAl}_{3} \mathrm{Be}_{2}{ }^{-}, \mathrm{CAl}_{2} \mathrm{Be}_{3}{ }^{2-}$, and $\mathrm{CAlBe}_{4}{ }^{3-}$. These $\mathrm{ppC}$ species are $\sigma$ and $\pi$ double aromatic. In comparison with their parents, these $\mathrm{H}$-attached molecules are more stable electronically, as can be reflected by the more favourable alternative negative-positive-negative charge-arranging pattern and the less dispersed peripheral orbitals. Remarkably, seven of these nine molecules are global energy minima, in which four of them are kinetically stable, including $\mathrm{CAl}_{3} \mathrm{Be}_{2} \mathrm{H}$ (2a), $\mathrm{CAl}_{2} \mathrm{Be}_{3} \mathrm{H}^{-}(4 \mathrm{a}), \mathrm{CAl}_{2} \mathrm{Be}_{3} \mathrm{H}_{2}$ (5a), and $\mathrm{CAlBe}_{4} \mathrm{H}_{4}{ }^{+}$(9a). They are the promising target for the experimental realization of species with a $\mathrm{ppC}$
\end{abstract}

Received 14th September 2018

DOI: $10.1039 / \mathrm{c} 8 \mathrm{ra0} 07664 \mathrm{~b}$

rsc.li/rsc-advances

In 2001, Wang and Schleyer reported a family of ppCcontaining molecules, i.e. the milestone "hyparenes", which were designed by substituting the $-(\mathrm{CH})_{n}$ - moieties in aromatic or even anti-aromatic hydrocarbons with ppC building blocks $-\mathrm{C}_{3} \mathrm{~B}_{3}-,{ }^{-} \mathrm{C}_{2} \mathrm{~B}_{4}-$, and $-\mathrm{CB}_{5}-{ }^{4 b}$ Subsequently, ppC species such as $\mathrm{CCu}_{5} \mathrm{H}_{5},{ }^{7} \mathrm{CBe}_{5}$ and $\mathrm{CBe}_{5}{ }^{4-},{ }^{8}$ wheel-like $\mathrm{C}_{2} \mathrm{~B}_{8}, \mathrm{C}_{3} \mathrm{~B}_{9}{ }^{3+}$ and $\mathrm{C}_{5} \mathrm{~B}_{11}{ }^{+}{ }^{9}$ were also proposed. However, it is still unknown to date whether these small ppC clusters are global minima on their potential energy surfaces. Hence, people cannot evaluate their experimental viability. Nonetheless, situation changed when Zeng and Schleyer group reported the first ppC global minimum $D_{5 \mathrm{~h}} \mathrm{CAl}_{5}{ }^{+}$in 2008, which features not only the $18 \mathrm{e}$ structure, but also the $\sigma$ and $\pi$ double aromaticity. ${ }^{10}$ Taking $\mathrm{CAl}_{5}{ }^{+}$as the seed structure and considering the periodicity as well as the diagonal relationship, etc., people had designed a series isoelectronic ppC structures, including $\mathrm{CAl}_{n} \mathrm{Be}_{m}{ }^{1-m}(m=1-3),{ }^{11} \mathrm{CAl}_{4} \mathrm{E}^{+}(\mathrm{E}=$ $\mathrm{Al}, \mathrm{Ga}, \mathrm{In}, \mathrm{Tl}),{ }^{12} \mathrm{CBe}_{5} \mathrm{E}^{-}(\mathrm{E}=\mathrm{Al}, \mathrm{Ga}, \mathrm{In}, \mathrm{Tl}),{ }^{13} \mathrm{CAl}_{4} \mathrm{TmX}_{2}(\mathrm{Tm}=$ $\mathrm{Ti}, \mathrm{Zr}, \mathrm{Hf} ; \mathrm{X}=\mathrm{F}, \mathrm{Cl}, \mathrm{Br}, \mathrm{I}$, and cyclopentadienyl anion), ${ }^{\mathbf{1 4}}$ and $\mathrm{CGa}_{n} \mathrm{Be}_{m}{ }^{1-m}(n+m=5, m=1-4) .{ }^{15}$

During the design of these species, when each $\mathrm{Al}$ or its heavier congeners was replaced by a Be atom, a negative charge was added to maintain the isoelectronic relationship. However, it would be hard to experimentally realize such ppC structures due to the high molecular charges and the exposure of the electron deficient metal atoms. As a result, people had tried to stabilize the highly negatively charged ppC ions through attaching the certain number of auxiliary atoms. For example, $\mathrm{H}$ atoms had been attached to $\mathrm{CAl}_{4}{ }^{-}$and $\mathrm{CAl}_{4}{ }^{2-}$ in a joint experimental-theoretical study, leading to the new ptC species 
$\mathrm{CAl}_{4} \mathrm{H}$ and $\mathrm{CAl}_{4} \mathrm{H}^{-} .^{16}$ For ppC species, the most studied seed structure should be $\mathrm{CBe}_{5}{ }^{4-}, \mathbf{8}$ which is even not an eligible minimum. ${ }^{17}$ Nevertheless, through attaching the auxiliary atoms, like alkali metals, hydrogen, halogens, and even transition metal gold, a family of ppC species can be designed, including $\mathrm{CBe}_{5} \mathrm{Li}_{n}{ }^{n-4}(n=1-5),{ }^{17 a} \mathrm{CBe}_{5} \mathrm{H}_{n}{ }^{n-4}(n=2,3,5),{ }^{17 b}$ $\mathrm{CBe}_{5} \mathrm{E}_{5}{ }^{+}(\mathrm{E}=\mathrm{F}, \mathrm{Cl}, \mathrm{Br}, \mathrm{Li}, \mathrm{Na}, \mathrm{K}),{ }^{18}$ and $\mathrm{CBe}_{5} \mathrm{Au}_{n}{ }^{n-4}(n=2-5) .{ }^{19}$ In these ppC species, the auxiliary atoms play the roles of both compensating the deficient electrons and reducing the high negatively charges. Remarkably, $\mathrm{H}$ atoms were also employed to stabilize the ppC-containing $\mathrm{C}-\mathrm{Be}$ double chain nanoribbon, where its $\mathrm{CBe}_{5} \mathrm{H}_{2}$ ppC unit possesses the similar electronic structures to that of $\mathrm{CAl}_{5}{ }^{+20}$

Very recently, using $\mathrm{Li}$ atoms to balance the high negative charge of Be-doped ppC structures results in neutral or monoanionic species $\left[\left(\mathrm{CAl}_{2} \mathrm{Be}_{3}\right) \mathrm{Li}\right]^{-11 b}$ and $\mathrm{CGa}_{n} \mathrm{Be}_{m} \mathrm{Li}_{m-1}(n+m=$ $5, m=1-4),{ }^{15}$ where Li atoms generally show high affinity to $\mathrm{Be}$ atoms. In addition, our recent study revealed that Be and $\mathrm{H}$ can be bounded together through favourable covalent and ionic bonding, ${ }^{5 c, 21}$ thus $\mathrm{H}$ should be a better choice than $\mathrm{Li}$ as the auxiliary atoms around $\mathrm{CBe}_{5} \mathrm{ppC}$ core. ${ }^{17 \boldsymbol{b}}$ Herein, we wonder whether $\mathrm{H}$ atoms can be attached onto the Be-doped ppC structures to design the new ppC molecules possessing the molecular charges with $\pm 1|e|$, which facilitates the experimental generation and accurate calculation. The answer is positive and presented in this computational study, which designed nine new ppC molecules (see Fig. 1), in which four of them are kinetically stable global minima, thereby providing promising targets for experimental realization.

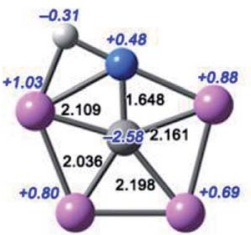

1a $\left(C_{s} \mathrm{CAl}_{4} \mathrm{BeH}^{+}\right)$

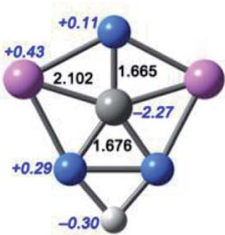

$4 \mathrm{a}\left(\mathrm{C}_{2 \mathrm{v}} \mathrm{CAl}_{2} \mathrm{Be}_{3} \mathrm{H}^{-}\right)$

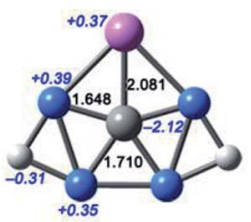

7a $\left(C_{2 v} \mathrm{CAlBe}_{4} \mathrm{H}_{2}^{-}\right)$

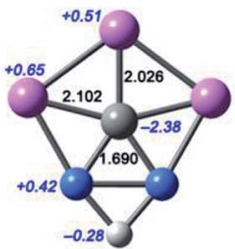

$2 \mathrm{a}\left(\mathrm{C}_{2 v} \mathrm{CAl}_{3} \mathrm{Be}_{2} \mathrm{H}\right)$

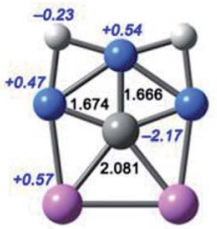

$5 \mathrm{a}\left(\mathrm{C}_{2 \mathrm{v}} \mathrm{CAl}_{2} \mathrm{Be}_{3} \mathrm{H}_{2}\right)$

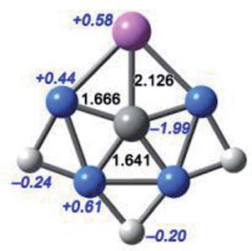

$8 \mathrm{a}\left(\mathrm{C}_{\mathrm{s}} \mathrm{CAIBe}_{4} \mathrm{H}_{3}\right)$

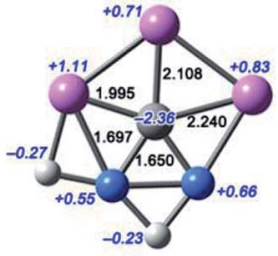

$3 \mathrm{a}\left(\mathrm{C}_{s} \mathrm{CAl}_{3} \mathrm{Be}_{2} \mathrm{H}_{2}{ }^{+}\right)$

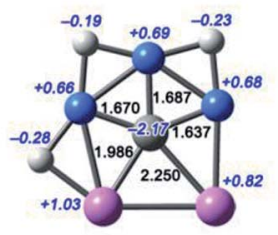

$6 \mathrm{a}\left(\mathrm{C}_{\mathrm{s}} \mathrm{CAl}_{2} \mathrm{Be}_{3} \mathrm{H}_{3}{ }^{+}\right)$

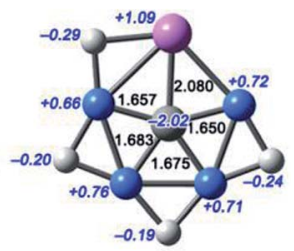

9a $\left(\mathrm{C}_{\mathrm{s}} \mathrm{CAIBe}_{4} \mathrm{H}_{4}{ }^{+}\right)$
Fig. 1 Optimized structures 1a-9a at the B3LYP/aug-cc-pVTZ level. Bond distances and NBO charges are given in black and italic blue fonts, respectively.

\section{Computational methods}

The ppC species designed in this work were optimized and harmonic vibrational frequencies analyzed at the B3LYP/aug-ccpVTZ level, which predicted these ppC structures to be true energy minima. The vibrations obtained using B3LYP functional was calibrated by the calculations using double hybrid functional B2PLYP $^{22}$ with D3 empirical dispersion correction (B2PLYP-D3), ${ }^{23}$ which gave the similar results to those obtained at the B3LYP level. So B3LYP functional should be reliable for current ppC molecules. The thermodynamic stability of designed ppC species was studied using a stochastic search algorithm. ${ }^{24}$ Two sets of explorations were run for singlet potential energy surfaces until they converged. The triplet potential energy surfaces were examined by another two sets of explorations as well. The randomly generated initial structures were optimized at the B3LYP/6-31G(d) level and 20 lowest isomers were recalculated at the B3LYP/aug-cc-pVTZ level, then ten lowest isomers were refined at the B2PLYP-D3/aug-cc-pVTZ level. Finally, the energies of the five lowest isomers were improved at the $\operatorname{CCSD}(\mathrm{T}) / \mathrm{aug}$-ccpVTZ level. The relative energies were compared using $\operatorname{CCSD}(\mathrm{T}) /$ aug-cc-pVTZ electronic energies plus B2PLYP-D3/aug-cc-pVTZ Gibbs free energy corrections. The wave function stability, natural bond orbital $(\mathrm{NBO})^{25}$ analyses and the nucleusindependent chemical shifts (NICS) ${ }^{26}$ analyses were performed at B3LYP/aug-cc-pVTZ. Adaptive nature density partitioning $(\text { AdNDP) })^{27}$ was carried out at B3LYP/6-31G(d) level. BornOppenheimer molecular dynamic (BOMD) ${ }^{28}$ simulations were run at the B3LYP/6-31g(d) level and $298 \mathrm{~K}$. The stochastic search algorithm was realized using GXYZ 2.0 program, ${ }^{29}$ the AdNDP analysis was performed using AdNDP program, the $\operatorname{CCSD}(\mathrm{T})$ calculations were carried out using MolPro 2012.1, ${ }^{30}$ the NBO analyses were performed using NBO $3.1,{ }^{31}$ and all other calculations were performed using the Gaussian 09 package. ${ }^{32}$

\section{Results and discussion}

\section{Design of $\mathrm{CAl}_{n} \mathrm{Be}_{m} \mathrm{H}_{x}^{q}(n+m=5, q= \pm 1, x=q+m-1)$}

In this work, we focus on four components, including $\mathrm{CAl}_{4} \mathrm{Be}$, $\mathrm{CAl}_{3} \mathrm{Be}_{2}{ }^{-}, \mathrm{CAl}_{2} \mathrm{Be}_{3}{ }^{2-}$, and $\mathrm{CAlBe}_{4}{ }^{3-}$ (see Fig. $\mathrm{S} 1 \dagger$ ), in which the global energy minima of former three components had been proved to be ppC structure previously. ${ }^{11}$ We had studied $\mathrm{CAlBe}_{4}{ }^{3-}$ and found that it is a ppC local energy minimum at the B3LYP/aug-cc-pVTZ level. However, its wavefunction is unstable, possibly due to the high negative charge, so reducing such charge is necessary. Using the four ppC species and their ppC-containing isomers as the seed structures, we try to attach $\mathrm{H}$ atoms onto the $\mathrm{Be}-\mathrm{Be}$ or $\mathrm{Be}-\mathrm{Al}$ edges. Considering molecular charges within $\pm 1|e|$, there are nine possible components, including $\mathrm{CAl}_{4} \mathrm{BeH}^{+}, \mathrm{CAl}_{3} \mathrm{Be}_{2} \mathrm{H}, \mathrm{Cal}_{3} \mathrm{Be}_{2} \mathrm{H}_{2}{ }^{+}, \mathrm{CAl}_{2} \mathrm{Be}_{3} \mathrm{H}^{-}, \mathrm{CAl}_{2}-$ $\mathrm{Be}_{3} \mathrm{H}_{2}, \mathrm{CAl}_{2} \mathrm{Be}_{3} \mathrm{H}_{3}{ }^{+}, \mathrm{CAlBe}_{4} \mathrm{H}_{2}{ }^{-}, \mathrm{CAlBe}_{4} \mathrm{H}_{3}, \mathrm{CAlBe}_{4} \mathrm{H}_{4}{ }^{+}$. Fig. 1 shows the most stable ppC structures (1a-9a) for each component. At the B3LYP/aug-cc-pVTZ level, 8a adopts the quasiplanar geometry, while other species adopt the perfectly planar structures. The $\mathrm{C}-\mathrm{Al}$ distances in 1a-9a range from 1.995 to $2.250 \AA$ and the $\mathrm{C}-\mathrm{Be}$ distances range from 1.641 to $1.710 \AA$, which are close enough to consider each of corresponding $\mathrm{Al}$ or 
Be atom as a coordination to $\mathrm{C}$ atom, so 1a-9a can be regarded as ppC or quasi-ppC species.

\section{Electronic structure analyses}

Orbital analysis. To better understand the chemical bonding in these ppC species, the adaptive natural density partitioning $(\text { AdNDP })^{27}$ analysis was performed and the results of $4 \mathbf{a}-\mathbf{6 a}$ are shown in Fig. 2, while those of other species are given in Fig. S2 in the ESI. $\dagger$ AdNDP is an extension of natural bond orbital (NBO) analysis. It represents the electronic structure of a molecular system in terms of $n$-center two-electron ( $n \mathrm{c}-2 \mathrm{e})$ bonds, with $n$ ranging from one to total number of atoms in the molecule. Thus, AdNDP recovers not only the Lewis elements (lone pairs and 2c-2e bonds), but also the delocalized $n c-2 \mathrm{e}$ bonds. As the first and second columns of these figures show, for any $\mathrm{Be}-\mathrm{Be}$ or $\mathrm{Be}-\mathrm{Al}$ edge without bridging $\mathrm{H}$ atom, there is a $2 \mathrm{c}-2 \mathrm{e} \sigma$ bond with occupation numbers (ONs) ranging from 1.98 to $1.99|e|$, while for that with a bridging $\mathrm{H}$ atom, there is a $\mathrm{Be}-\mathrm{H}-\mathrm{Be}$ or $\mathrm{Be}-\mathrm{H}-\mathrm{Al}$ three-center two-electron $(3 \mathrm{c}-2 \mathrm{e})$ bond $(\mathrm{ON}=1.95-1.98|e|)$. We note that the $3 \mathrm{c}-2 \mathrm{e}$ bonds are less dispersed than $2 \mathrm{c}-2 \mathrm{e}$ bonds, indicating that occupying such bonds may be beneficial to the molecular stability. Consistently, as shown in Table 1, for species with the same ppC core (except for $\mathrm{CAl}_{4} \mathrm{Be}$ core), their HOMO-LUMO gaps are enlarged with the increasing number of attached $\mathrm{H}$ atoms. For instance, $\mathrm{CAl}_{2}$ $\mathrm{Be}_{3}{ }^{2-}, \mathbf{4 a}, 5 \mathbf{a}$, and $6 \mathbf{a}$ have zero, one, two, and three $\mathrm{H}$ atoms attaching to the common $\mathrm{CAl}_{2} \mathrm{Be}_{3}$ core, their HOMO-LUMO gaps are $0.94,2.66,2.86$, and $2.96 \mathrm{eV}$, respectively, showing the obvious increasing trend. The pictures shown in third to fifth column are the delocalized six-center two-electron (6c-2e) $\sigma$ bonds $(\mathrm{ON}=1.99-2.00|e|)$ and those in the last column are the $6 \mathrm{c}-2 \mathrm{e} \pi$ bonds $(\mathrm{ON}=1.98-2.00|e|)$. These orbitals are essentially identical to their parent molecules, which describe the ligandto-ppC interactions. Remarkably, three $6 c-2 e \sigma$ bonds and one $6 \mathrm{c}-2 \mathrm{e} \pi$ bonds fill eight electrons to the valence shell of $\mathrm{C}$ atoms, meeting the octet rule, which would be a reason why these ppC species can be stable.

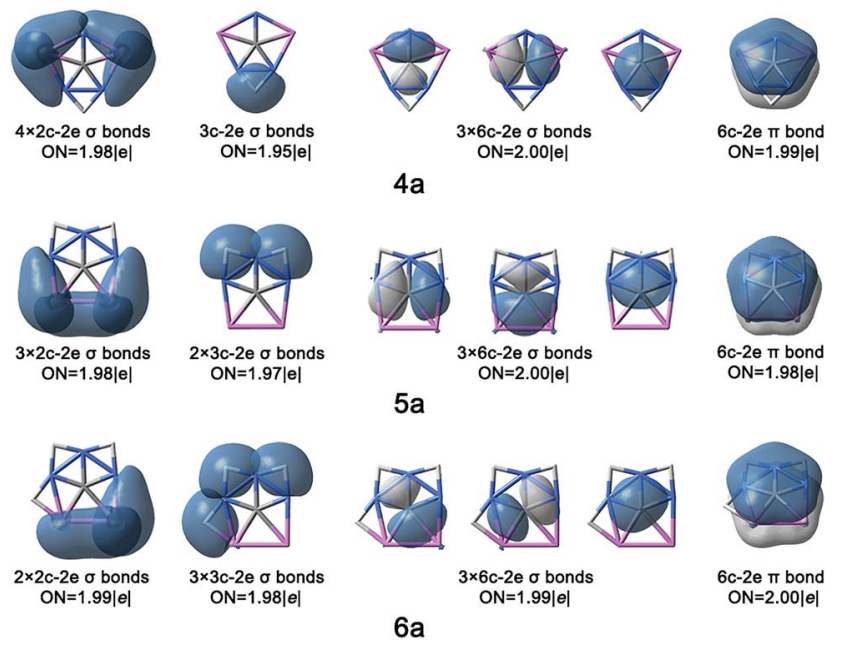

Fig. 2 AdNDP bonding patterns of $4 a, 5 a$ and $6 a$ with occupation numbers (ONs).
Aromaticity. In addition to offering the stable shell structure for carbon, three delocalized $\sigma$ orbitals and one delocalized $\pi$ orbitals in these ppC species match the $4 n+2$ rule, where $n=$ 0 and 1 , respectively, so these ppC species may be $\sigma$ and $\pi$ aromatic, similar to their parents molecules. To verify the orbital analysis results, we further conducted the NICS analysis, a powerful tool to evaluate the aromaticity. As shown in Fig. 3 and S3, $\uparrow$ the concerned points were chosen according to molecular symmetry and the ghost atoms were placed for these points from $0 \AA$ (within molecular plane) up to $2 \AA$ above the molecular plane. Similar to the situation in their parent molecules, which was previously proved to be aromatic, the NICS values for the concerned point in the ppC molecules reported in this work are all negative (shown in red balls). Therefore, the NICS analyses confirmed the orbital analysis results that the molecules were aromatic. We think the aromaticity should be another factor to stabilize these ppC species.

Ionic and covalent bonding. We also performed the conventional $\mathrm{NBO}^{25}$ analysis. The ionic bonding was evaluated by natural charge distribution. As shown in Fig. 1, the NBO charges on carbon of 1a-9a are largely negative, ranging from -1.99 to $-2.58|e|$, while those on beryllium $(+0.29$ to $+0.76|e|)$ and aluminum $(+0.37$ to $+1.11|e|)$ are positive. This suggests the obvious charge transfer from $\mathrm{Be}$ and $\mathrm{Al}$ to $\mathrm{C}$, similar to the situation in their parent molecules. Nevertheless, different from them, there are peripheral hydrogen atoms in 1a-9a, which possess the small but non-negligible negative charges $(-0.19$ to $-0.31|e|)$, so the ionic bonding in 1a-9a is more favourable than in $\mathrm{CAl}_{5}{ }^{+}$because of more efficient alternative negative-positivenegative charge distribution patterns. The covalent bonding was assessed by the Wiberg bond indices (WBI). As shown in Table 1, the $\mathrm{WBI}_{\mathrm{C}-\mathrm{Al}}$ and $\mathrm{WBI}_{\mathrm{C}-\mathrm{Be}}$ values, $0.30-0.45$ and $0.50-0.83$, respectively, indicate the multicenter peripheral to center covalent bonding interactions. The $\mathrm{WBI}_{\mathrm{Al}-\mathrm{H}}$ and $\mathrm{WBI}_{\mathrm{Be}-\mathrm{H}}$ values range from 0.27 to 0.64 , implying the formation of $\mathrm{Be}-\mathrm{H}-\mathrm{Be}$ or $\mathrm{Be}-\mathrm{H}-\mathrm{Al}$ $3 \mathrm{c}-2 \mathrm{e}$ bonds. The WBI analysis results are consistent with the AdNDP analyses described above. The NBO analyses results revealed that both ionic and covalent bonding contribute significantly to the stabilization of ppC species 1a-9a.

\section{Stability consideration}

Thermodynamic and kinetic stability. The experimental viability of small clusters is closely related to their thermodynamic and kinetic stabilities. In this work, the stochastic search algorithm $^{24}$ was employed to explore the thermodynamic stability. As shown in Fig. S4 in ESI, $\dagger \mathbf{1 a}$ and 3a are higher than their global energy minimum by 10.7 and $3.8 \mathrm{kcal} \mathrm{mol}^{-1}$, respectively, at the final CCSD(T)/aug-cc-pVTZ level, thus 19 and 3a will not be viable experimentally and they are disregarded in the following. In contrast, $2 \mathbf{a}$ and $\mathbf{4 a - 9 a}$ are proved to be global energy minima on their PES, being respectively 4.6, 3.1, 4.6, 3.6, $3.7,2.8$ and $15.0 \mathrm{kcal} \mathrm{mol}^{-1}$ lower than their corresponding second lowest isomers at the $\operatorname{CCSD}(\mathrm{T}) /$ aug-cc-pVTZ level. The good thermodynamic stability will benefit their generation in the gas-phase experiment.

Next, we studied the kinetic stability of global energy minima 2a and 4a-9a by performing 50 pico-second (ps) Born- 
Table 1 The lowest vibrational frequencies $\left(v_{\mathrm{min}}\right.$, in $\left.\mathrm{cm}^{-1}\right), \mathrm{HOMO}-\mathrm{LUMO}$ gaps (gap, in eV), vertical detachment energies (VDE, in eV), vertical electron affinities (VEA, in eV), and the Wiberg bond indices (WBIs) for selected atom-atom interactions

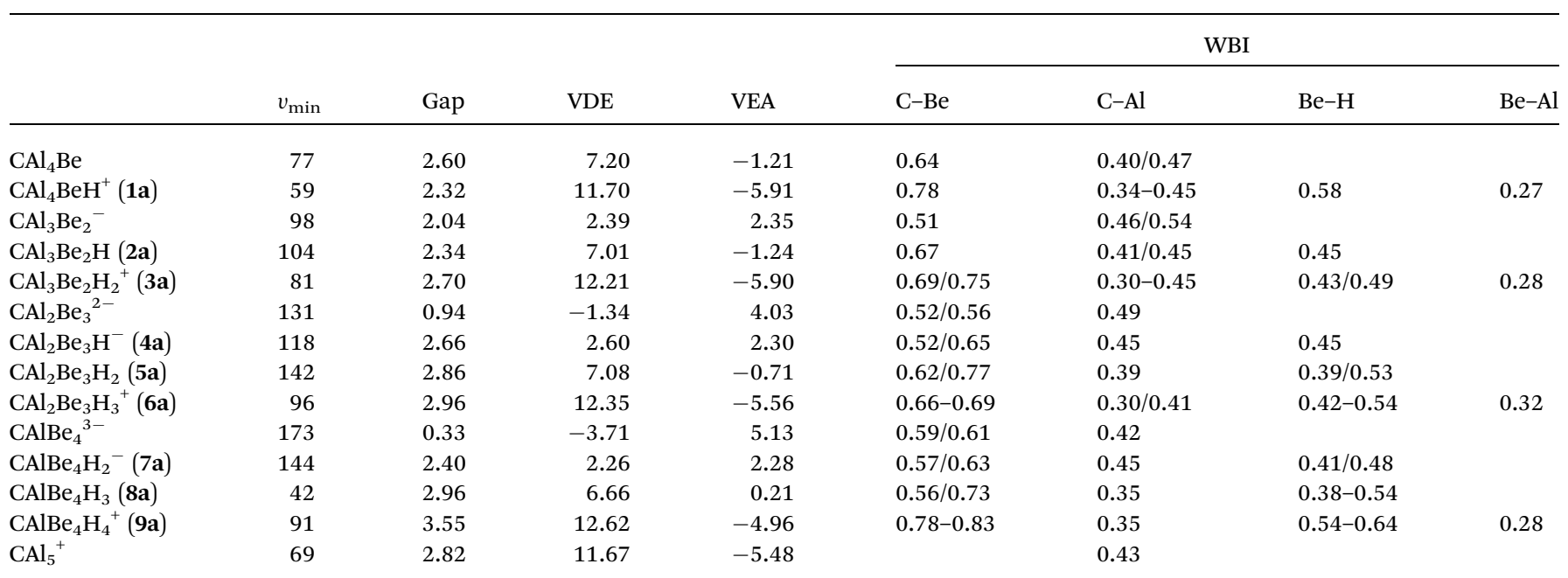
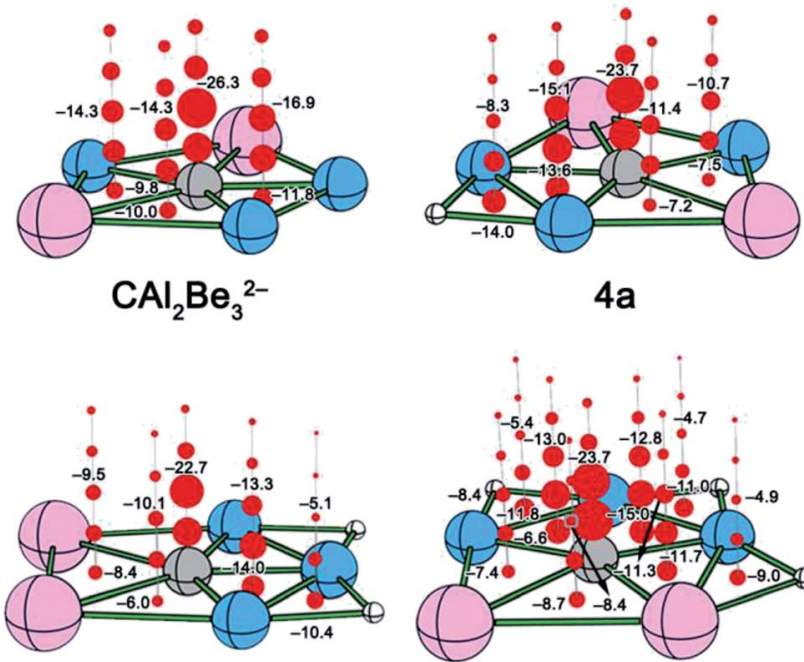

$5 a$

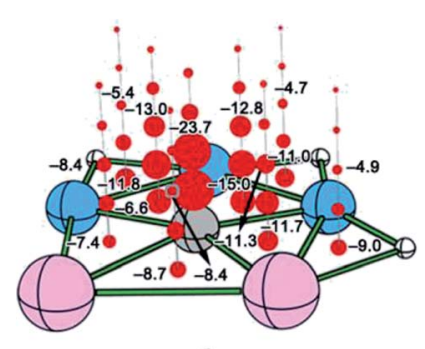

$6 a$

Fig. 3 NICS of $\mathrm{CAl}_{2} \mathrm{Be}_{3}{ }^{2-}$ and $4 a-6 a$. Points with negative NICS values (shown in red balls) are aromatic.

Oppenheimer molecular dynamic (BOMD) ${ }^{28}$ simulations at the B3LYP/6-31G(d) level and $298 \mathrm{~K}$. The structural evolution during the simulation was described by the root-mean-square deviation (RMSD) relative to their B3LYP/6-31G(d)-optimized structures. As shown in Fig. 4, the RMSD plots of 6a-8a show irreversible upward jumps at about 34, 32, and 9 ps, respectively. Structural sampling suggested that the upward jumps of these RMSD plots correspond to the isomerization processes, so 6a-8a are kinetically unstable. As a comparison, the RMSD values of $\mathbf{2 a}, \mathbf{4 a}$, and $\mathbf{5 a}$ have no upward jump and the fluctuation also relatively small, ranging from $0.06,0.08$, and 0.09 to $0.47,0.45$ and $0.48 \AA$. The RMSD plot of 9a shows some reversible jumps. However, the highest RMSD value is only 0.80 $\AA$, which corresponds to the flexibility of $\mathrm{H}$ atoms rather than the tendency to isomerize the structure. The average RMSD values for these four molecules are also small, being $0.22,0.24$,

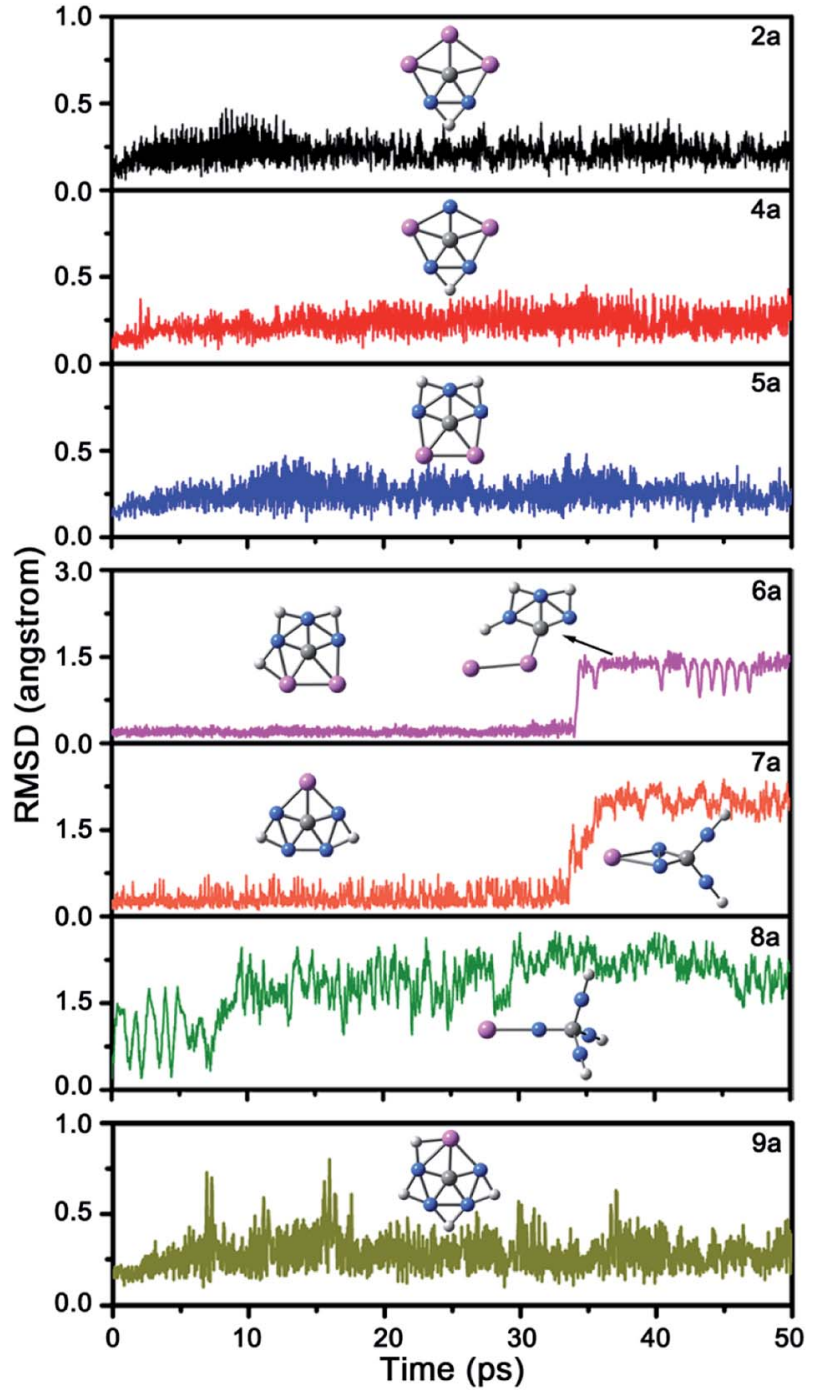

Fig. 4 The RMSD plots for the BOMD simulations of $2 a$ and $4 a-9 a$ at $298 \mathrm{~K}$. 
0.25 and $0.29 \AA$ A , respectively. The dynamic simulations suggest their structures can be well-maintained during the simulations at $298 \mathrm{~K}$. Being the kinetically stable global energy minima, 2a, 4a, 5a, and 9a would be promising targets for gas phase generation and followed spectroscopic characterization.

VDES and VEAs. To give experimentalists the reference data, we have calculated the VDEs and VEAs of these molecules. Here, we only discuss $\mathbf{2 a}, \mathbf{4 a}, \mathbf{5 a}$, and $\mathbf{9 a}$. For mono-anionic global minimum 4a, its VDE is $2.60 \mathrm{eV}$, which reasonably high for photoelectron spectroscopy, while its VEA, $2.26 \mathrm{eV}$ suggest that gaining an electron is endothermic. For neutral global minima 2a and 5a, their VDEs of 7.01 and $7.08 \mathrm{eV}$ as well as the VEAs of -1.24 and $-0.71 \mathrm{eV}$ indicate their low tendency to lose or gain an electron. For mono-cation 9a, it VEA value of $-4.96 \mathrm{eV}$ ranges between that of $\mathrm{Na}^{+}(-5.14 \mathrm{eV})$ and $\mathrm{K}^{+}(-4.30 \mathrm{eV})$, so its VEA is rather low in cations. Simultaneously, its VDE of $12.62 \mathrm{eV}$ indicate its low tendency to lose an electron.

\section{Conclusion}

In summary, we have designed nine ppC species with molecular charges within $\pm 1|e|$ through attaching the $\mathrm{H}$ atoms at the $\mathrm{Be}-$ Be or Be-Al edge of ppC species $\mathrm{CAl}_{4} \mathrm{Be}, \mathrm{CAl}_{3} \mathrm{Be}_{2}{ }^{-}, \mathrm{CAl}_{2} \mathrm{Be}_{3}{ }^{2-}$, and $\mathrm{CAlBe}_{4}{ }^{3-}$. Similar to their parent molecules, these ppC species meet the octet rule and feature the $\sigma$ and $\pi$ double aromaticity. The introduction of $\mathrm{H}$ atoms on these ppC structures does not obviously influence the ppC core structure both geometrically and electronically, but can enlarge the HOMOLUMO gaps, convert the dispersed Be-Be or Be-Al 2c-2e $\sigma$ bonds to the less dispersed $\mathrm{Be}-\mathrm{H}-\mathrm{Be}$ or $\mathrm{Be}-\mathrm{H}-\mathrm{Al} 3 \mathrm{c}-2 \mathrm{e} \pi$ bonds, which further stabilize the ppC structures. In these nine $\mathrm{H}$-attached ppC species, four of them were confirmed to be stable both thermodynamically and kinetically, including $\mathrm{CAl}_{3} \mathrm{Be}_{2} \mathrm{H}(\mathbf{2 a})$, $\mathrm{CAl}_{2} \mathrm{Be}_{3} \mathrm{H}^{-}$(4a), $\mathrm{CAl}_{2} \mathrm{Be}_{3} \mathrm{H}_{2}$ (5a), and $\mathrm{CAlBe}_{4} \mathrm{H}_{4}{ }^{+}$(9a). They are the promising targets for generation and characterization in the gas phase experiments.

\section{Conflicts of interest}

There are no conflicts to declare.

\section{Acknowledgements}

The authors acknowledge support for this work from the NSFC (Grant No. 21720102006, 21273140, and 21471092), the Special Program for Applied Research on Supercomputation of the NSFC-Guangdong Joint Fund (the second phase) (Grant No. U1501501), the One Hundred-Talent Program of Shanxi Province, the Program for Outstanding Innovative Teams of Higher Learning Institutions of Shanxi, the Shanxi 1331KIRT, the Foundation of the State Key Laboratory of Coal Conversion (Grant No. J17-018-610), and the Shanxi University supercomputing platform.

\section{Notes and references}

1 H. J. Monkhorst, Chem. Commun., 1968, 1111.
2 R. Hoffmann, R. W. Alder and C. F. Wilcox Jr, J. Am. Chem. Soc., 1970, 92, 4992.

3 J. B. Collins, J. D. Dill, E. D. Jemmis, Y. Apeloig, P. v. R. Schleyer, R. Seeger and J. A. Pople, J. Am. Chem. Soc., 1976, 98, 5419.

4 (a) K. Exner and P. v. R. Schleyer, Science, 2000, 290, 1937; (b) Z. X. Wang and P. v. R. Schleyer, Science, 2001, 292, 2465.

5 (a) L. M. Yang, E. Ganz, Z.-F. Chen, Z. X. Wang and P. v. R. Schleyer, Angew. Chem., Int. Ed., 2015, 54, 9468and the references therein. (b) H. Li, X. Tian, X. M. Luo, M. Yan, Y. Mu, H. G. Lu and S.-D. Li, Sci. Rep., 2017, 7, 5701; (c) X.-F. Zhao, J.-J. Li, H. Li, C. Yuan, X. Tian, S.-D. Li, Y.-B. Wu, J.-C. Guo and Z.-X. Wang, Phys. Chem. Chem. Phys., 2018, 20, 7217.

6 (a) V. Vassilev-Galindo, S. Pan, K. J. Donald and G. Merino, Nat. Rev. Chem., 2018, 2, 0114and the references therein. (b) P. Liu, J.-H. Bian, Q. Wang, F. Huang, D. Li and Y.-B. Wu, Phys. Chem. Chem. Phys., 2018, 20, 12642; (c) S. Pan, J. L. Cabellos, M. Orozco-lc, P. K. Chattaraj, L. L. Zhao and G. Merino, Phys. Chem. Chem. Phys., 2018, 20, 12350.

7 S. D. Li, C. Q. Miao and G. M. Ren, Eur. J. Inorg. Chem., 2004, 2232.

8 Q. Luo, Sci. China, Ser. B: Chem., 2008, 51, 1030.

9 S. Erhardt, G. Frenking, Z. Chen and R. S. P. Schleyer, Angew. Chem., Int. Ed., 2005, 44, 1078.

10 Y. Pei, W. An, K. Ito, P. v. R. Schleyer and X. C. Zeng, J. Am. Chem. Soc., 2008, 130, 10394.

11 (a) J. O. C. Jimenez-Halla, Y.-B. Wu, Z.-X. Wang, R. Islas, T. Heine and G. Merino, Chem. Commun., 2010, 46, 8776; (b) Y.-B. Wu, Y. Duan, H. G. Lu and S.-D. Li, J. Phys. Chem. A, 2012, 116, 3290.

12 X. Y. Zhang and Y. H. Ding, Comput. Theor. Chem., 2014, 1048, 18.

13 A. C. Castro, G. Martinez-Guajardo, T. Johnson, J. M. Ugalde, Y.-B. Wu, J. M. Mercero, T. Heine, K. J. Donald and G. Merino, Phys. Chem. Chem. Phys., 2012, 14, 14764.

14 Z. H. Cui, V. Vassilev-Galindo, J. L. Cabellos, E. Osorio, M. Orozco, S. Pan, Y. H. Ding and G. Merino, Chem. Commun., 2017, 53, 138.

15 S. Pan, J. L. Cabellos, M. Orozco-Ic, P. K. Chattaraj, L. L. Zhao and G. Merino, Phys. Chem. Chem. Phys., 2018, 20, 12350.

16 J. Xu, X. Zhang, S. Yu, Y.-h. Ding and K. H. Bowen, J. Phys. Chem. Lett., 2017, 8, 2263.

17 (a) R. Grande-Aztatzi, J. L. Cabellos, R. Islas, I. Infante, J. M. Mercero, A. Restrepo and G. Merino, Phys. Chem. Chem. Phys., 2015, 17, 4620; (b) J. C. Guo, G. M. Ren, C. Q. Miao, W. J. Tian, Y. B. Wu and X. T. Wang, J. Phys. Chem. A, 2015, 119, 13101.

18 J.-C. Guo, W.-J. Tian, Y.-J. Wang, X.-F. Zhao, Y.-B. Wu, H.-J. Zhai and S.-D. Li, J. Chem. Phys., 2016, 144, 244303.

19 J.-C. Guo, L. Y. Feng, X.-Y. Zhang and H. J. Zhai, J. Phys. Chem. A, 2018, 122, 1138.

20 J.-J. Li, Y. Mu, X. Tian, C. Yuan, Y.-B. Wu, Q. Wang, D. Li, Z.-X. Wang and S.-D. Li, J. Mater. Chem. C, 2017, 5, 408.

21 (a) Y.-B. Wu, J. L. Jiang, R. W. Zhang and Z.-X. Wang, Chem.Eur. J., 2010, 16, 1271; (b) X.-F. Zhao, H. Li, C. Yuan, Y.-Q. Li, 
Y.-B. Wu and Z.-X. Wang, J. Comput. Chem., 2016, 37, 261; (c) C. Yuan, X.-F. Zhao, Y.-B. Wu and X. Wang, Angew. Chem., Int. Ed., 2016, 55, 15651; (d) Z.-Z. Qin, Q. Wang, C. Yuan, Y.-T. Yang, X.-F. Zhao, D. Li, P. Liu and Y.-B. Wu, Dalton Trans., 2018, 47, 4707.

22 S. Grimme, J. Chem. Phys., 2006, 124, 034108.

23 (a) S. Grimme, S. Ehrlich and L. Goerigk, J. Comput. Chem., 2011, 32, 1456; (b) L. Goerigk and S. Grimme, J. Chem. Theory Comput., 2011, 7, 291.

24 (a) M. Saunders, J. Comput. Chem., 2004, 25, 621; (b) P. P. Bera, K. W. Sattelmeyer, M. Saunders, H. F. Schaefer and P. v. R. Schleyer, J. Phys. Chem. A, 2006, 110, 4287.

25 A. E. Reed, L. A. Curtiss and F. Weinhold, Chem. Rev., 1988, 88, 899.

26 (a) P. v. R. Schleyer, C. Maerker, A. Dransfeld, H.-J. Jiao and N. J. R. E. Hommes, J. Am. Chem. Soc., 1996, 118, 6317; (b)
Z. F. Chen, C. S. Wannere, C. Corminboeuf, R. Puchta and P. v. R. Schleyer, Chem. Rev., 2005, 105, 3842.

27 D. Y. Zubarev and A. I. Boldyrev, Phys. Chem. Chem. Phys., 2008, 10, 5207.

28 J. M. Millam, V. Bakken, W. Chen, W. L. Hase and H. B. Schlegel, J. Chem. Phys., 1999, 111, 3800.

29 H. G. $\mathrm{Lu}$ and Y.-B. Wu, in GXYZ 2.0: A Random Search Program, Shanxi University, Taiyuan, China, 2015.

30 H.-J. Werner, et al., in MolPro 2012.1, University College Cardiff Consultants Limited, Cardiff, UK, 2012.

31 E. D. Glendening, A. E. Reed, J. E. Carpenter and F. Weinhold, NBO Version 3.1., 1990.

32 M. J. Frisch, et al., in Gaussian 09 Revision D.01, Gaussian Inc., Wallingford, CT, 2013. 